\title{
O CONTEXTO COMO ACONTECIMENTO: MODOS DE CONSTRUÇÃO DO TEXTO NA EXPERIÊNCIA JORNALÍSTICA DE ORGANIZAÇÕES NÃO- GOVERNAMENTAIS
}

\author{
THE CONTEXT AS EVENT: TEXT CONSTRUCTION MODES IN THE JOURNALISTIC \\ EXPERIENCE OF NON-GOVERNMENTAL ORGANIZATIONS \\ El CONTEXTO COMO ACONTECIMIENTO: MODOS DE CONSTRUCCIÓN DEL TEXTO \\ EN LA EXPERIENCIA PERIODÍSTICA DE ORGANIZACIONES NO GUBERNAMENTALES
}

\author{
Elton Antunes \\ Doutor, Universidade Federal de Minas Gerais \\ eantunes@ufmg.br \\ Carolina Silveira \\ Mestre \\ silveiracarolina@yahoo.com.br
}

\section{Resumo}

O objetivo deste artigo é discutir a dimensão jornalística de materiais produzidos por organizações não governamentais voltadas para intervenção no debate público sobre os direitos da infância. A partir do boletim "Prioridade Absoluta", produzido pela ONG Oficina de Imagens, a análise volta-se para o modo como os textos produzem um universo de referências acerca da temática de maneira a inscrevê-lo, ao mesmo tempo, como produto jornalístico e sugestão de pauta para a imprensa de referência.

Palavras-chave: Jornalismo. Acontecimento. Infância.

\begin{abstract}
The objective of this article is to discuss the journalistic dimension of informative materials produced by non-governmental organizations devoted to taking part in the public debate about children's rights. From the bulletin "Prioridade Absoluta", produced by the NGO Oficina de Imagens, the analysis focus on the ways that texts produce a universe of references about the theme in question, becoming, at the same time, journalistic products and story suggestions (press releases) for the mainstream press.
\end{abstract}

Keywords: Jornalism. Event. Childhood. 


\section{Resumen}

Este artículo tiene el objetivo de discutir la dimensión periodística de materiales producidos por organizaciones no gubernamentales dedicadas a la intervención en el debate público sobre los derechos de la niñez. A partir del boletín "Prioridade Absoluta”, producido por la ONG Oficina de Imagens, el análisis enfoca la manera como los textos crean un universo de referencias respecto a la temática en cuestión de modo a inscribirlo simultáneamente como producto periodístico y sugerencia de pauta (comunicado de prensa) para los medios de referencia.

Palabras clave: Periodismo. Acontecimiento. Niñez.

\section{INTRODUÇÃO}

Organizações e movimentos sociais protagonizam, junto com iniciativas do setor governamental, empresarial, do universo religioso, dentre tantos outros, um processo que vem sendo percebido e tematizado como uma tomada da cena jornalística. Em uma via, aponta-se uma qualificação para o relacionamento com a mídia, com o treinamento das fontes, o monitoramento da cobertura, a veiculação de contra-informação, dentre outras possibilidades. Por outra via, faz-se referência a uma produção jornalística própria, veiculada nos mais diversos dispositivos, para audiências que não se restringem aos públicos imediatos das organizações e com grande semelhança em relação aos formatos e esquemas narrativos dos meios jornalísticos tradicionais. Nos dois caminhos, a dimensão tecnológica é apontada com destaque. A própria ideia de uma atuação em rede para o trabalho de produção, difusão e critica de conteúdos informativos tem sua emergência fortemente associada a mudanças nos suportes tecnológicos dos meios de comunicação. Esse cenário chega mesmo a ser tematizado como uma crise (FAUSTO NETO, 2009), visto que os diferentes sujeitos não se limitam a trocar informações, o fazem com a roupagem do jornalismo e, por vezes, descortinando práticas antes vistas exclusivamente nas redações.

Inúmeras reflexões se dedicam a pensar sobre os impactos de tais iniciativas, seja na perspectiva de abalos negativos ao sistema jornalístico ou pelo viés de um incremento ao debate plural e aberto, como vemos em Waisbord (2009) a respeito do que o autor denomina de jornalismo de defesa civil. Contudo, parece-nos que pouco se discute sobre como tais 
iniciativas configuram seus textos jornalísticos propriamente, ou seja, sobre o modo como, a partir das gramáticas da área, operam a construção de materiais discursivos voltados para a referencialização jornalística do mundo, seja em suas mídias próprias ou nas ações dedicadas a incidir naquilo que se produz nas mídias tradicionais. Não assumimos, de saída, que tais experiências possam ser tomadas como autênticos produtos jornalísticos, entendidos como aqueles produzidos em instituições com redações autônomas e de acordo com protocolos profissionais. Mas tomamos como pressuposto que há, sim, uma tentativa de fazer com tais propostas se inscrevam no universo do jornalismo.

A discussão proposta neste artigo pretende avaliar uma dessas experiências no âmbito do chamado Terceiro Setor ${ }^{1}$ - aqui nomeado por “jornalismo feito em casa” - de forma a caracterizar os materiais discursivos aí produzidos a partir da maneira como buscam referencializar o mundo. A análise toma por referência, especificamente, a experiência jornalística da organização não-governamental Oficina de Imagens. Com sede em Belo Horizonte, capital de Minas Gerais, a Oficina é uma das dez instituições que integram hoje um coletivo intitulado Rede ANDI Brasil - Rede de Comunicadores pelos Direitos da Infância, que tem por objetivo contribuir para uma cobertura jornalística mais atenta aos direitos da criança e do adolescente. Essas organizações atuam com base em uma metodologia comum que abrange o monitoramento e a análise da cobertura jornalística sobre a infância em seus respectivos estados, o investimento na aproximação entre jornalistas e fontes de informação e a produção de materiais informativos e educativos diversos. O trabalho em rede é realizado desde o ano 2000 e teve origem na iniciativa pioneira da ANDI, fundada em 1991 por jornalistas que acompanharam a mobilização em torno da aprovação do Estatuto da Criança e do Adolescente, que se deu em 1990. A experiência se organiza, portanto, em torno do propósito claro de intervir no debate público em torno do tema, sobretudo naquele travado nos veículos midiáticos de referência, por meio da produção de materiais que apresentam diferentes componentes jornalísticos.

\section{PROCEDIMENTOS METODOLÓGICOS}

\footnotetext{
${ }^{1}$ O Terceiro Setor em geral abarca diferentes instituições e movimentos sociais, considerados sob o prisma de novas maneiras de associativismo, de ação coletiva, e cujas iniciativas são marcadas por diversidade ideológica e de formas de ação, mas com um discurso comum em torno dos chamados temas da "cidadania”. (ALVAREZ et al., 2000; GOHN, 2001)
} 
Para a análise, tomamos como referente empírico o informativo eletrônico intitulado “Prioridade Absoluta”, que se constitui como uma sugestão de pauta enviada à imprensa e cujo nome faz referência ao artigo 227 da Constituição Federal, que coloca como dever da família, da sociedade e do Estado assegurar com absoluta prioridade os direitos de crianças, adolescentes e, desde 2010, dos jovens. A produção é feita por jornalistas e todas as organizações da Rede ANDI Brasil veiculam o material com esse nome, acrescentando a sigla do estado em questão. Assim, em Minas Gerais, temos o "Prioridade Absoluta - MG: a pauta dos direitos da criança e do adolescente”. As organizações têm autonomia para definir o perfil gráfico e editorial do material, assim como seu modo de circulação. Mas, em linhas gerais, o boletim é enviado com a identificação “Sugestão de Pauta” no assunto do email. Há um texto principal acompanhado de "Sugestões de fontes", com a indicação de nomes, instituições e contatos. O material também traz pequenas notas secundárias. É enviado por meio eletrônico, prioritariamente para jornalistas e, em alguns estados, alcança um público maior e mais diverso, como é o caso de Minas Gerais. Em 12 anos de atuação junto à Rede ANDI Brasil, a Oficina de Imagens já produziu em torno de 440 edições, enviadas nos últimos anos para um público de aproximadamente 3.300 pessoas. O acervo encontrava-se disperso, do que decorre alguma imprecisão no número total de boletins.

A primeira etapa da análise consistiu na classificação temática das 429 edições veiculadas entre 2000 e 2010 que puderam ser localizadas, com base em procedimentos da análise de conteúdo. Como indica Bauer (2008, p.191), a análise de conteúdo "não pode nem avaliar a beleza, nem explorar as sutilezas de um texto particular”, mas “pode ser o primeiro passo na ordenação e caracterização dos materiais em um enorme esforço de pesquisa” (2008, p. 213). Apoiamo-nos, ainda, na concepção de que a análise de conteúdo ajuda a inferir um dado contexto, o que é relevante para a leitura que se segue, orientada pelo propósito de explorar o modo de referencialização operado pelos boletins. Em seguida, tendo em perspectiva os procedimentos metodológicos da análise da narrativa, tais como explorados por Motta (2005), optamos pela escolha de um conjunto de boletins dentro de um mesmo tema, de forma a favorecer a apreensão de uma organização retórica em torno de uma problemática e, com isso, permitir explorar melhor a referencialização proposta pelos boletins. Tratamos de “juntar o que a dinâmica da atividade jornalística separa. Reunir as notícias diárias em 
episódios e seqüências maiores, como se fossem um acontecimento único e singular” (MOTTA, 2005, p.3).

Em um universo de 34 temas identificados, privilegiamos aquele que mais provocações pareceu-nos oferecer às indagações da pesquisa: as "medidas socioeducativas”. O nome "medidas socioeducativas" remete a um conjunto de providências determinadas pelo Estatuto da Criança e do Adolescente para a responsabilização dos adolescentes que cometem atos infracionais. Quando o ato é praticado por uma criança, os pais devem responder pela infração. Aos maiores de 12 anos, são seis as medidas: Advertência, Obrigação de Reparar o Dano, Prestação de Serviços à Comunidade, Liberdade Assistida, Semiliberdade e Internação. Dentre os temas elencados na pesquisa, a questão do envolvimento dos adolescentes com atos infracionais é uma dos que melhor representa a mudança de paradigma colocada pelo Estatuto da Criança e do Adolescente. A legislação anterior, denominada Código de Menores (Lei $\mathrm{n}^{0}$ 6.697, de 10 de outubro de 1979), tinha por foco o recolhimento e a guarda de crianças e adolescentes abandonados, órfãos e autores de atos infracionais. A nova legislação assumiu novas referências com repercussão na maneira de lidar com a chamada questão infracional, que passa a ser enfrentada por um viés educativo.

Apesar dos vários avanços mais de duas décadas depois, o envolvimento dos adolescentes com atos infracionais ainda motiva debates acalorados sobre a efetividade do Estatuto. Casos de grande repercussão de violências cometidas por adolescentes sempre vêem acompanhados do debate em torno da redução da idade penal. É o que se viu em 2007, por exemplo, quando o menino João Hélio, de seis anos de idade, foi assassinado no Rio de Janeiro após um assalto ao carro em que estava com sua mãe e sua irmã. O garoto ficou preso ao cinto de segurança e foi arrastado do lado de fora do carro. Um adolescente foi um dos cinco acusados de envolvimento no crime. O caso foi abordado pelos principais veículos jornalísticos nacionais e parte da cobertura foi dedicada a repercutir argumentos favoráveis à redução da idade penal.

A partir dos boletins com o tema medidas socioeducativas, buscamos ver como essa experiência propõe um texto jornalístico, explorando a forma como inscreve ações, atores, espaços, tempos e relações causais. Embora tais entradas de leitura dialoguem com uma "gramática" (o que, quem, onde, quando, como e por que) frequentemente operada na perspectiva de apreensão do mundo como algo a ser meramente retratado, tomamos essas dimensões por outra visada. Entendemo-las como um quadro de leitura que permite ao 
jornalismo fazer falar um mundo, nem refleti-lo e nem criá-lo. Assim, não nos detivemos em reconstruir as histórias contadas, como se dotadas de um desenvolvimento e uma cronologia evidentes. Privilegiamos o modo de contar, buscando ver como o texto jornalístico "feito em casa” se particulariza nessa escrita. A questão não é, portanto, entender o que o texto jornalístico proposto por uma organização da sociedade civil tem a nos dizer, mas como nos diz. Assim, a análise não se prende à seqüência cronológica dos boletins, os visa, ao contrário, de maneira solidária e concomitante.

Para isso, mobilizamos um conceito alargado de texto, que abrange algo que é da ordem do tecido, mas também um fazer permanente. Conforme Leal e Antunes (2011, p.22), "retomar a etimologia como inspiração pode ser um passo nesse caminho: texto que vem de textu (tecido) e de textere (fazer com fios, tramar, urdir). Logo, um “texto” surge como obra tecida e como um tecer”. Diríamos que buscamos ver um texto possível que, embora se apóie em inscrições concretas, não está dado de antemão nessa aparição mais evidente. Consideramos que o texto comunicativo, compreendido como aquele que se desenha por uma perspectiva relacional da comunicação, não se define pela materialidade que vai de um polo a outro, ao contrário, toma forma no bojo das relações múltiplas e complexas que ele mesmo permite implicar. O desafio passa a ser apreender então um texto que é fecho, registro, mas que também é, sobretudo, abertura, um universo de possíveis.

\section{O CONTEXTO COMO UMA DIMENSÃO CHAVE DO ACONTECIMENTO}

O que acontece pelas páginas do boletim “Prioridade Absoluta”? Em que tempo e espaço? Por quais razões? Como as ações se desenvolvem? Que atores são implicados nesse desenvolvimento? Antes de explorar as possíveis respostas a tais perguntas, retomamos algumas características do material analisado. O boletim "Prioridade Absoluta” se orienta pelo propósito institucional de contribuir para uma melhor atenção à cobertura sobre os direitos da criança e do adolescente. Nos anos iniciais, o material era enviado apenas aos jornalistas, por meio do fax. Com a internet, passou a ser compartilhado com um público mais amplo. As marcas do diálogo com as redações se mantêm em inscrições mais óbvias, como a indicação ao final do texto principal das sugestões de fontes, com os respectivos contatos, mas também em preocupações mais gerais, como o cuidado na veiculação com certa antecedência dos eventos e outras ocorrências indicadas na pauta, de forma a possibilitar a cobertura do 
jornalista. Mas há também indícios de um relato que se propõe como texto "publicado", resultado final de um trabalho jornalístico, o que se vê na própria forma de organização textual, com a referência, por exemplo, a falas em discurso direto e indireto, apresentadas como decorrentes de processos de entrevistas. Longe de ser um problema, essa "dupla personalidade” parece-nos constituir a própria riqueza do material, enquanto objeto de pesquisa.

A grande maioria dos boletins dedicados às medidas socioeducativas é iniciada colocando em cena uma diversidade de eventos: encontros, debates, mobilizações, audiências e ocasiões em que há divulgação de relatórios lançados recentemente. Com raras exceções, os boletins fazem referência já nos textos das chamadas e de abertura à determinação de circunstâncias de tempo e espaço dos eventos reportados. Assim sendo, há um “o quê” mais imediato que é representado por essas ocorrências. Tais eventos se referem sempre a episódios relacionados ao debate do tema e nunca a ocorrências específicas relativas ao envolvimento dos adolescentes com o ato infracional. Os boletins também não se detêm em explicar os eventos que coloca em cena. Não detalha, por exemplo, programações. Sendo uma sugestão de pauta, também não relata o desenvolvimento das discussões realizadas nos eventos que lhe servem de gancho.

Mas do que falam os boletins? Nos anos iniciais, os boletins desse recorte temático colocaram em cena, a partir de eventos e mobilizações, a questão da redução da idade de responsabilização penal, deixando evidente um posicionamento contrário à proposta. A partir de 2002, entra em cena a discussão em torno da precariedade das medidas socioeducativas, foco que se mantém em todos os demais anos. Apenas em 2007, a discussão em torno da redução da idade penal ganha novamente força em função do assassinato do menino João Hélio, quando os boletins chegaram a fazer referência a esse caso. Vemos, portanto, que as ocorrências empíricas operam como efetivamente "ganchos jornalísticos” para o debate de uma situação mais ampla, a ideia de que os adolescentes envolvidos com atos infracionais são vítimas da negligência do Estado e da sociedade. A tentativa de fazer referência ao mundo dos direitos da criança e do adolescente em uma dimensão acontecimental se realiza por dois gestos. Primeiro, por uma tentativa de atualizar a situação mais geral por meio de ocorrências específicas. O segundo gesto se coloca no esforço em fazer emergir a questão central mais ampla como um desvio, uma anormalidade, algo que não deveria ser invisível, afinal 
representa uma inversão na lógica de que o Estado e a sociedade devem proteger e não violar.

No boletim de número 259, temos o seguinte título e chamadas:

\section{Repensando as medidas socioeducativas}

Resolução do Conanda institui novo modelo para a execução de medidas socioeducativas

Anteprojeto de lei sobre o tema será apresentado na Câmara dos Deputados, em julho

Relatório apresentará a realidade dos centros de internação no país

(Boletim 259, 2006)

As chamadas apontam para três ações diferentes, todas localizáveis no tempo e no espaço: O Conanda (Conselho Nacional dos Direitos da Criança e do Adolescente) “institui”; anteprojeto “será apresentado”; e relatório “apresenta”. Já na abertura do texto, contudo, um universo de referência específico é mobilizado: “Um em cada três adolescentes e jovens brasileiros que cumprem medida socioeducativa estão em meio fechado (...). Esse percentual inverte [grifo nosso] a lógica do Estatuto da Criança e do Adolescente (...)”. Mais à frente o boletim localiza a proposta do Sinase (Sistema Nacional de Atendimento Socioeducativo), repercute mais dados sobre a situação dos adolescentes e detalhas as seis medidas socioeducativas. Vejamos mais um trecho do boletim 259:

Dados do Instituto de Pesquisa Econômica Aplicada (IPEA), de 2002, indicam que $71 \%$ das unidades de internação não têm ambiente físico adequado, sendo que 39\% possuem alas de isolamento - o que não é permitido pelo ECA - e 40\% não possuem material escolar apropriado em suas salas de aula. Outro agravante é a presença de adolescentes em presídios e delegacias: segundo a Secretaria Especial de Direitos Humanos da Presidência da República (SEDH), em 2004 havia 383 jovens nesses espaços, o que também vai de encontro à Lei. Esses são apenas alguns dos dados levantados pelo Sinase que apontam para a necessidade de se repensar a cultura prisional no Brasil. (Boletim 259, 2006).

Vejamos um segundo exemplo, com trechos do boletim 66. Mais uma vez, têm-se um evento - o Fórum Metropolitano e, ao mesmo tempo, com maior destaque, a denúncia mais geral, “revelada” pelas estatísticas.

\section{$O$ adolescente estigmatizado}

Mesmo com as estatísticas a seu favor, o jovem continua sendo o culpado pelo aumento da violência 
A violência é uma realidade cada vez mais próxima. Casos de pessoas roubadas, seqüestradas ou até mesmo assassinadas multiplicam-se no nosso dia-a-dia. Costuma-se colocar, na sociedade em geral, que adolescentes e crianças socialmente excluídas são as grandes causadoras deste boom da violência. A proposta da redução da imputabilidade penal de 18 para 16 anos comprova essa tendência.

É nesse contexto que o painel "Jovem: gerador e vítima da violência”, um dos oito temas a serem debatidos no $1^{\circ}$ Fórum Metropolitano Contra a Violência, vai debater a relação do adolescente com a violência. (...)

Estatísticas do Juizado da Infância e da Juventude de BH revelam [grifo nosso] que aproximadamente $72 \%$ dos crimes cometidos por adolescentes em Belo Horizonte, no ano de 1999, foram contra o patrimônio, e 6,65\% contra a vida. (...). Qual seria o efeito da convivência de jovens de 16 anos com detentos mais velhos e perigosos? A redução da imputabilidade não seria uma forma de atacar a conseqüência ao invés da causa? (...)

(Boletim 66, 2002)

Os boletins não abordam diretamente os atos infracionais praticados pelos adolescentes. Contudo, como nos mostra Mouillaud (2002, p.39): “(...) produzir uma superfície visível induz um invisível como seu avesso (...)”, é uma presença que ‘insiste’ ou ‘subsiste’ (...)” (MOUILLAUD, 2002, p. 41). Essa região de sombra é parte daquilo que se mostra. A partir dessa perspectiva, observamos que há um privilégio do boletim a uma dimensão de contextualização e que esse gesto se conecta a um mundo não diretamente tematizado, mas que é parte de sua narrativa. Na verdade, para indicar que o boletim incide em um determinado quadro de particularização é necessário considerar que ele parte de ocorrências singulares, embora não as tematize diretamente. Afinal, a condição de existência do contexto é haver tal referência primeira. Essa leitura evidencia a necessidade de se pensar em um conceito alargado de texto, pressuposto apontado anteriormente.

E como os atores são implicados nessa construção? O texto do boletim é construído com o recurso à fala de outras pessoas, que são relatadas em discurso direto e indireto, nos moldes característicos do relato jornalístico. Observa-se a preocupação em respaldar todas as informações em vozes que representam lugares institucionais, em detrimento das opiniões e depoimentos de pessoas comuns. Tendo em vista que a questão central gira em torno do debate das políticas públicas, os atores mobilizados dizem desse universo. Há quatro atores centrais implicados na tematização dos adolescentes envolvidos em ato infracional enquanto vítimas da negligência do Estado e da sociedade: o executivo, a sociedade civil representada por Fóruns e Frentes da área, o Sistema de Justiça e os próprios adolescentes. 
O executivo representa um dos atores centrais, sendo também a fonte jornalística mais recorrente, sobretudo na esfera estadual. O governo do Estado é interpelado a dar explicações sobre os investimentos e as condições de execução das medidas de meio fechado e figura como um vilão. De maneira geral, o boletim denuncia precariedades na estrutura de atendimento e nos investimentos. O próprio envolvimento dos adolescentes com o ato infracional aparece representado como resultado de uma série de violações de direitos. Nesse ponto específico, cumpre lembrar que os boletins sobre as medidas são parte de uma tessitura maior, em que é marcante a reivindicação de direitos básicos nas áreas de saúde, educação e assistência social. Vejamos, a seguir, alguns trechos que ilustram tal responsabilização do executivo:

Ao contrário do que muitas pessoas pensam, os adolescentes infratores não ficam impunes. O Estatuto da Criança e do Adolescente prevê um conjunto de medidas sócio-educativas para ressocializá-los. De acordo com o documento que será encaminhado para a audiência, "o que ocorre é a negligência do governo e da sociedade em geral [grifo nosso] que não dispõem, e nem se empenham em dispor, dos meios necessários para a realização das medidas legais que possibilitam a inclusão social desses cidadãos”. (Boletim 18, 2001)

Ele [Mário Volpi] acredita que a boa aplicação ou não das medidas são decisivas para o que o adolescente será na vida. "Ou o estado dá uma oportunidade [grifo nosso] a este adolescente regressar de forma digna para a comunidade, ou o adolescente consolida o universo da marginalidade", diz. (Boletim 132, 2003)

A falta de recursos e de infra-estrutura compromete a aplicação de medidas socioeducativas a adolescentes que violam as leis nas pequenas e médias cidades de Minas Gerais. (Boletim 162, 2004)

Em Minas, um dos problemas enfrentados é a falta de vagas e a conseqüente superlotação na internação provisória. (...) De acordo com a Secretaria de Estado de Defesa Social, está prevista para este ano a inauguração de um centro com 56 vagas em Juiz de Fora e, em 2008, devem ser construídos mais três unidades no estado. (Boletim 297, 2007)

A área socioeducativa é uma das que apresenta ações com baixa execução, como a Estruturação do Sistema de Gestão Socioeducativo, que não gastou nada dos R\$ 60 mil que lhe foram autorizados. Em nota, a Secretaria de Estado de Defesa Social (SEDS) explicou [grifo nosso] que esses recursos estavam destinados basicamente à logística de encontros e plenárias e custeio de diárias, e que até o final do ano os recursos serão executados. (Boletim 363, 2008) 
Em nota, a Secretaria de Estado de Defesa Social de Minas Gerais alega [grifo nosso] que está tomando medidas contra a superlotação. (...) De acordo com dados do Siafi (Sistema Integrado de Administração Finaneira), até o dia 11 de julho, apenas 1,36\% dos recursos previstos no orçamento do estado para a construção de unidades socioeducativas havia sido executado. (Boletim 344, 2008)

Um manifesto de repúdio à superlotação e à situação precária do Centro de Internação Provisória (CEIP) Dom Bosco, que fica no bairro Horto, em Belo Horizonte, veio à tona recentemente revelando inúmeras violações [grifo nosso] aos direitos dos adolescentes que aguardam a definição da medida socioeducativa. (...) Em nota, a Suase não comentou o manifesto e se limitou [grifo nosso] a informar os investimentos que vêem sendo feitos. (Boletim 384, 2009)

Um segundo ator central na trama e que figura em segundo lugar no ranking das fontes é representado pela sociedade civil organizada por meio de Fóruns e Frentes na área e, secundariamente, pelas próprias organizações da sociedade civil. Esses atores figuram como os protagonistas das ações dedicadas a enfrentar a situação de negligência em relação aos adolescentes. São também os responsáveis pelas boas iniciativas retratadas. A seguir, alguns trechos que ilustram essa representação:

Um movimento realizado pelo Conselho Nacional dos Direitos da Criança e do Adolescente - CONANDA -, a Frente de Defesa dos Direitos da Infância e da Adolescência de Minas Gerais, a ONG Associação de Apoio à Criança e ao Adolescente - AMENCAR-, Instituto de Estudos Socio-Econômicos INESP- e outras instituições nacionais não só conseguiu adiar a votação para Fevereiro de 2001 como sugerir ao Deputado Inaldo Leitão, Relator das PECs, uma audiência pública, para propor subsídios à argumentação da questão jurídica com relação a cláusula pétrea. (Boletim 12, 2000)

Mais de 200 instituições de Minas Gerais estão se mobilizando para impedir a redução da maioridade penal no Brasil. (Boletim 18, 2001)

ONG executa medida com sucesso

Criado há dois anos e meio, o Projeto Marista Crescendo é o responsável pelo encaminhamento dos adolescentes que devem prestar serviços à comunidade da Regional Oeste. (Boletim 93, 2002)

O Centro de Desenvolvimento Humano e Profissional São Marcelino Champagnat (Projeto Marista CrerSendo), de Belo Horizonte, é um exemplo de aplicação bem sucedida das medidas previstas no ECA. (Boletim 132, 2003)

Para tentar suprir essa ineficiência do sistema e articular ações para efetivação das medidas socioeducativas, várias entidades envolvidas no 
trabalho com adolescentes autores de ato infracional criaram a Rede de Medidas Socioeducativas. O objetivo da Rede é melhorar as políticas de atendimento aos adolescentes em conflito com a lei, oferecendo um atendimento como previsto no Estatuto com uma proposta pedagógica capaz de promover a ressocialização desses jovens. (Boletim 142, 2003)

Um terceiro ator central na trama corresponde ao Sistema de Justiça, mas prioritariamente na figura do Ministério Público. Esse ator aparece como um observador crítico e como um agente de acusação. A inscrição do Sistema de Justiça se dá, sobretudo, na perspectiva de uma validação das críticas e das cobranças realizadas pela sociedade civil. Vejamos, a seguir, alguns trechos:

De acordo com o promotor da infância e juventude, Ronald Albergaria, uma das maiores necessidades para melhorar a rede de atendimento é a regionalização com a construção de centros para a aplicação das medidas socioeducativas. (Boletim 141, 2003)

O promotor da Vara da Infância e Juventude, Ronald Albergaria, afirma que a situação desses adolescentes em cadeias públicas é "imoral” e contraria o ECA e a Doutrina da Proteção Integral das Nações Unidas. (Boletim 143, 2003)

Sob a alegação de que o Centro de Internação Provisória Dom Bosco (CEIP) está superlotado e funcionando em condições precárias, a Promotoria da Infância e Juventude de Belo Horizonte e a Defensoria Pública de Minas Gerais ajuizaram duas ações civis públicas solicitando a interdição da unidade, localizada na região Leste de Belo Horizonte. (...) As ações pedem a interdição do Centro e a transferência dos adolescentes para um local apropriado. Segundo Wellerson, o pedido da Defensoria também inclui a reforma das instalações do CEIP, a indenização dos adolescentes e multa para o Governo do Estado. (Boletim 278, 2007)

O promotor da Infância e da Juventude de Belo Horizonte, Celso Penna, também é contrário à redução da idade penal e ao aumento do tempo de internação. "A redução significaria substituir a aplicação do ECA, que é uma lei desconhecida, pelo Código Penal, que é a lei mais discriminatória que existe na face da terra”, afirma. (Boletim 281, 2007)

Um último ator é representado pelo próprio adolescente, que embora seja o pivô de toda a discussão, não chega a ter voz autônoma nos boletins. Ora figura como vítima do Estado e da sociedade, ora como objeto da ação de enfrentamento dos Fóruns e Frentes. Há, evidentemente, uma dificuldade maior de acesso aos adolescentes para a realização de 
entrevistas. Além disso, como o boletim não chega a discutir casos localizados, parece não criar condições para a colocação das vozes desses adolescentes. Por essa perspectiva, contudo, o adolescente não figura como interlocutor em um debate que privilegia a política pública. Os trechos a seguir são ilustrativos das questões colocadas. No primeiro, embora seja possível supor que o relato se baseia na conversa com o adolescente, em nenhum momento sua fala é reproduzida por meio de discurso direto ou indireto. No segundo, a condição de entrevista fica ressaltada, mas o discurso direto também não é utilizado:

Em pichações incompreensíveis para a maior parte das pessoas, o estudante Júlio César Fernandes, 17, exprimia sua revolta com a sociedade e também tentava conquistar fama e reconhecimento no grupo de amigos. A atitude, no entanto, o levou a ser flagrado pela polícia e, como prevê o Estatuto da Criança e do Adolescente, foi punido com a medida de prestação de serviços à comunidade. A situação abriu uma perspectiva para Júlio. Ele foi encaminhado ao projeto CrerSendo, onde aprendeu a substituir as pichações por linhas bem traçadas e pelas cores vibrantes do Grafite. (Boletim 149, 2003)

Com 19 anos, ela já passou quatro vezes por centros de internação, por assalto a mão armada, tráfico de drogas, porte ilegal de armas e formação de quadrilha. A última internação terminou no ano retrasado. Durante a entrevista, com o filho de dois meses no colo, a jovem conta que, desde que saiu, está buscando uma vida sem complicações. Ia voltar a estudar, mas a gravidez adiou os planos. Com a ajuda do programa Tocando em frente, do qual participa há um ano, Pablina está reformando a casa da mãe, onde vai morar com seu filho. Ela fala que, sem a ajuda do projeto, não sabe para onde iria. (...)

O Tocando em frente, programa pioneiro em Minas Gerais no apoio a egressos de centros de internação, chama atenção para essa e outras necessidades das famílias e jovens que vivem essa realidade. A iniciativa é realizada pela Pastoral do Menor da Arquidiocese de Belo Horizonte em parceria com a Secretaria de Estado de Defesa Social de Minas Gerais. (Boletim 237, 2005)

Em síntese, os boletins articulam entrevistas variadas, mas na perspectiva de uma mesma enunciação. Entre a sociedade civil que denuncia e promove ações, o Ministério Público que acusa e o governo que se defende, prevalece o argumento de que há uma negligência em relação a esses jovens. Os posicionamentos se repetem ao longo dos boletins. São histórias que seguem abertas, sem encontrar um término, o que, de alguma maneira, evidencia a vocação de pauta do boletim. 
No que se refere a um “onde”, vemos que o boletim lida com três dimensões espaciais. Em primeiro lugar, há o espaço em que se desenvolvem as ações que são mobilizadas como gancho dos boletins: o espaço dos eventos, encontros, assembléias, mobilizações. Como já indicado, os boletins não se detêm em descrever essas ocorrências ou em reportar as discussões e, assim, tais espaços figuram apenas como uma localização, com a indicação breve e pontual do endereço dos encontros.

Um segundo espaço, também pouco evidente, é aquele objeto das denúncias colocadas. De maneira explícita, o boletim se refere basicamente aos centros de internação e aos locais em que se dão o cumprimento das medidas de meio aberto. Algumas das expressões utilizadas apontam, no caso da internação, para um cenário de deterioração: superlotação, precário, etc. Importante dizer que a referência a esse espaço não se dá com base no testemunho daqueles que produzem o boletim: as descrições são feitas por outras pessoas. Esse espaço físico é, portanto, um lugar de que se fala e os próprios adolescentes não tomam parte nesse relato. Uma terceira dimensão, contudo, parece-nos a principal. Ela se refere ao espaço da discussão da política pública, que pode materializar-se em eventos específicos, mas que se caracteriza pelo próprio encontro de opiniões. Na maior parte do tempo, o boletim faz ver esse fórum, constituindo-se ele próprio uma materialização de tal encontro.

Pelos aspectos já pontuados, é difícil indicar um desenvolvimento da narrativa em uma perspectiva linear. A questão da negligência se materializa em baixos investimentos que, por sua vez, levam às precariedades denunciadas. Mas não há episódios marcados, que possam indicar a narrativa de um estado de transformação do mundo do qual se fala. Assim, parecenos que há uma narrativa circular em que as situações e argumentos são retomados edição a edição. A negligência aparece, ainda, como decorrente da falta de informação e de interesse dos agentes públicos e da sociedade em geral. Essas características se tornam evidentes no tom didático assumido pelo boletim. Em várias de suas edições, as medidas socioeducativas são listadas e explicadas. Os boletins se dirigem muitas vezes de maneira a reforçar seu lugar de autoridade para o leitor: "entenda as seis medidas socioeducativas”.

A dimensão do “quando" é analisada em último lugar por oferecer elementos interessantes para a rearticulação das questões anteriormente pontuadas. Além disso, representa o aspecto mais desafiador na leitura dos boletins, visto que o "Prioridade Absoluta" se constitui na articulação de diferentes vocações que se definem fortemente pela dimensão do 
tempo. Se considerado como um relato publicado, inscreve-se na dimensão de um irrevogável, de fatos consumados. Se considerado como uma sugestão de pauta, oferece-se como uma promessa, um vir a ser de acontecimentos. Ele representa, portanto, ao mesmo tempo, um resultado e uma promessa, uma leitura de mundo e uma provocação à leitura a ser feita posteriormente por um jornalista.

O boletim toma como ponto de partida a ação de negligência da sociedade e do Estado em relação ao adolescente. Posiciona, portanto, tal situação em um nível de constatação. Em função desse cenário, a sociedade civil organizada em Frentes e Fóruns se mobiliza em ações de denúncia, mobilização e enfrentamento. O boletim nos conta que essa é a ação em desenvolvimento. Importante lembrar que a marcação de data, local e hora se dá em função dessas iniciativas: elas irão ocorrer em um futuro próximo, distante no máximo uma semana da data de veiculação do material. Diante dessa informação, o jornalista pode optar por dar repercussão à ação relatada pelo boletim e os demais leitores podem, inclusive, optar por participar dessas ações. Desse engajamento, poderá ocorrer uma maior responsabilização do Estado e, consequentemente, o atendimento adequado aos direitos dos adolescentes que cometem atos infracionais. A conseqüência maior esperada é o não envolvimento desses adolescentes com tais atos e a não reincidência.

A ação dos adolescentes parece situar-se em um antes e um depois. O boletim parte da negligência de que são vítimas enquanto autores de ato infracional. Isso implica haver o reconhecimento de que, antes da negligência, há uma ação dos adolescentes. Na outra ponta, essa ação aparece como uma possibilidade: sua concretização depende do engajamento da sociedade e do estado. Note-se que tal rol de iniciativas não aparece como dependente do próprio adolescente. Tais situações permanecem em um fora de campo do mundo de referência apontado, o que acaba por ser coerente com a ausência das vozes dos adolescentes: eles efetivamente não estão no boletim. Mas é importante lembrar, como já destacado, que a sombra ou o avesso estão sempre presentes. Assim, propomos que o boletim nos oferece o encadeamento temporal representado a seguir, em que destacamos em negrito o campo de visibilidade privilegiado: Adolescente comete ato infracional $>>$ Estado negligente com os adolescentes (constatado) >> sociedade civil se mobiliza (em desenvolvimento) >> engajamento dos cidadãos (mobilização esperada) >> envolvimento dos adolescentes com os atos infracionais (futuro em que se pode intervir). 
É importante perceber, contudo, que todas as dimensões elencadas co-existem. A negligência do Estado, a mobilização da sociedade civil, o engajamento dos cidadãos e o envolvimento dos adolescentes com os atos infracionais estão imbricados em um mesmo passado, presente e futuro. Estão, todos, em desenvolvimento. Contudo, observamos um jogo interessante em que a esfera de ação do adolescente é colocada fora de campo, ou como algo para o qual não se olha ou como uma situação passível de ser modificada.

O boletim faculta, portanto, aos seus leitores a possibilidade de uma intervenção na ação do próprio adolescente. O olhar “interessado” se particulariza em uma escrita que se propõe com um encadeamento que tenta projetar um futuro, colocando as condições presentes para a sua concretização ou modificação. Ele emerge chamando atenção para um passado de negligências, tenta instaurar descontinuidades e aponta consequências possíveis com base na leitura do presente. Contudo, esse passado só emerge na ação mesmo da denúncia e o futuro desenhado é uma ação que nasce no movimento social.

Essa leitura se mostra convergente com um modo de vislumbrar a emergência do movimento social. Conforme Mendonça (2007, p.124), [...] “é o próprio emergir da coletividade que permite a constituição do passado como marcado por práticas desrespeitosas e do futuro como espaço de construção de outros mundos possíveis”. Assim, aponta Mendonça (2007), a ação dos movimentos sociais pode ser analisada como uma proposta de refundação em que a emergência de interpretações imprevistas, que propõem novos modos de convívio, promove a interrupção de daquilo que seria um fluxo automático da vida. Conforme Mendonça (2007, p.138), “entendidos como acontecimento, em seu puro devir, movimentos são essa potência de ação que profetizam sobre o passado e o futuro, permitindo a permanente construção da realidade”.

O esforço em destacar certo contexto de referência por uma dimensão acontecimental se reveste, nessa perspectiva, de uma interessante dimensão de advocacy. Conforme Quéré (2005), o acontecimento pode ser compreendido como uma ruptura, como aquilo que desestabiliza e provoca um inquérito coletivo com vistas a domesticá-lo e reintegrá-lo ao curso normal da vida. O boletim não trata de acontecimentos, mas mobiliza o jornalismo enquanto uma processualidade que se define, em grande medida, pelo esforço em tomar o mundo em uma dimensão acontecimental. Agindo assim, dá a ver um esforço em provocar rupturas que possam mobilizar entendimentos, ações, mudanças. Para isso, ao contrário de domesticar, forja oferecer uma história aberta, sem desfecho, algo como um "você (também) 
decide”. Se, como diz Motta (2005, p.5), é a expectativa em torno do desenlace das histórias que mantém as notícias nos jornais ou telejornais, a insistência do boletim tende a se prolongar por bastante tempo.

\section{CONSIDERAÇÕES FINAIS}

Para além de considerar que a própria existência de iniciativas como a da Rede ANDI Brasil representam um elemento perturbador ao sistema jornalístico - para o seu desenvolvimento ou para a sua crise - buscamos ver as problematizações possíveis quando tais experiências são visadas pela escrita jornalística efetivamente proposta. Não colocamos em cena a causa tematizada, por ela mesma, mas a forma como ela se realiza em um texto que se apresenta para o campo jornalístico. Isso significa assumir que o "feito em casa”, no âmbito de uma organização da sociedade civil organizada, guarda as marcas desse lugar “interessado”, mas que esse olhar perito tem muito mais a dizer sobre a prática jornalística do que simplesmente dar visibilidade a temas considerados negligenciados.

Como um primeiro tensionamento, parece-nos que a leitura proposta aos boletins traz certo desconforto à ideia de que as relações temporais se ofereçam de maneira tão evidente ao olhar do jornalista ou que possam ser tomadas como uma propriedade dos acontecimentos. Como aponta Antunes (2009, p.86), “o acontecimento não aparece, do ponto de vista temporal, como tão facilmente delimitável”. Isso implica ver que, antes de representar uma cobertura "parcial”, o "feito em casa” descortina o universo de escolhas da própria imprensa de referência. E não se trata apenas de uma escolha entre dar ou não visibilidade a determinados temas, mas da própria relação de causalidade no tempo e no espaço que é proposta aos acontecimentos. O adolescente ou o "menor", esta última expressão combatida pelos militantes da área da infância, estão nos dois lugares, mas a forma como são considerados em um determinado espectro temporal pode colocá-los como um ponto de partida ou de chegada. E isso não é algo provocado pelas próprias ocorrências. "O acontecimento jornalístico se esparrama sobre diferentes temporalidades e tem seu início e fim como pontos de flutuação de operações sujeitas ao contexto sócio-cultural, à própria dinâmica editorial e às modalidades narrativas que irão representá-lo”. (ANTUNES, 2009, p.86). 
Ainda nessa perspectiva e como um segundo tensionamento vemos que o modo de operar dos boletins chama atenção para o quão previsíveis podem ser aqueles acontecimentos que mobilizam as atenções públicas. Isso exige certa prudência ao se propor, do ponto de vista da análise de tais situações, um recorte muito colado na emergência mesmo desses acontecimentos que irrompem. Inclusive para que se possa observar as conexões propostas, é importante tentar ir além de perceber o desenvolvimento empírico da ocorrência em si - o adolescente que se envolve em um ato criminoso, do qual resulta a morte de uma criança mas colocar em evidência as relações causais que não se deduzem apenas dessa cobertura mais imediata e óbvia. Ou seja, é preciso cuidado para que não se reduza o texto em torno dos acontecimentos ao registro do conjunto de matérias que tentam dar conta daquela ocorrência. Pelo “jornalismo feito em casa” evidencia-se que, também na imprensa de referência, a sombra é parte constituinte da esfera de visibilidade.

\section{REFERÊNCIAS}

ALVAREZ, Sônia E., DAGNINO, Evelina e ESCOBAR, Arturo (org.) Cultura e Política nos Movimentos Sociais latino-americanos: novas leituras. Belo Horizonte: UFMG, 2000.

ANTUNES, Elton. Enquadramento: considerações em torno de perspectivas temporais para a notícia. Revista Galáxia, 85 São Paulo, n. 18, p.85-99, dez. 2009.

BAUER, M. Análise de conteúdo clássica: uma revisão. M. BAUER; G. GASKELL (eds.), Pesquisa qualitativa com texto, imagem e som: um manual prático. $7^{\mathrm{a}}$ ed. Petrópolis, Vozes, 2008, p.189-217.

BRASIL. Constituição Federal. Presidência da República, 1990.

Disponível em: http://www.planalto.gov.br/ccivil_03/constituicao/constituiçao.htm. Acesso em 22 de maio de 2011.

BRASIL. Estatuto da Criança e do Adolescente. Presidência da República, 1990. Disponível em: http://www.planalto.gov.br/ccivil_03/Leis/L8069.htm. Acesso em 22 de março de 2011.

CONANDA. Sistema Nacional de Atendimento Socioeducativo - SINASE. Brasília, 2006. Disponível em www.direitoshumanos.gov.br/sedh/.arquivos/.spdca/sinase_integra1.pdf. Acesso em 10 de novembro de 2011.

LEAL, Bruno S. e ANTUNES, Elton. O acontecimento como contéudo: limites e implicação de uma metodologia. In: LEAL, Bruno Sousa; ANTUNES, Elton; VAZ, Paulo 
Bernardo. (orgs.). Jornalismo e acontecimento: percursos metodológicos. Florianópolis: Insular, 2011. p.17-36.

FAUSTO NETO, Antônio. Jornalismo: sensibilidade e complexidade. In: Revista Galáxia, São Paulo, n. 18, p.17-30, dez. 2009. Disponível em

http://revistas.pucsp.br/index.php/galaxia/issue/view/208. Acesso em 29 de novembro de 2010.

GOHN, Maria da Glória. Mídia, Terceiro Setor e MST. Petrópolis: Vozes, 2001.

MENDONÇA, Ricardo Fabrino. Movimentos sociais como acontecimentos: linguagem e espaço público. In: Lua Nova, São Paulo, 2007, p. 115-142.

MOUILLAUD, Maurice. O jornal: da forma ao sentido. 2 ed. Brasília: Editora Universidade de Brasília, 2002.

MOTTA,L.G.. A Análise Pragmática da Narrativa Jornalística. In: CONGRESSO BRASILEIRO DE CIÊNCIAS DA COMUNICAÇÃO, 28., 2005. Rio de Janeiro. Anais... São Paulo: Intercom, 2005. CD-ROM.

QUÉRÉ, Louis. Entre o facto e sentido: a dualidade do acontecimento. In: Trajectos, Revista de Comunicação, Cultura e Educação, n.6. Lisboa, ISCTE, Casa das Letras, 59-75, 2005.

WAISBORD, Silvio. A sociedade civil pode mudar o jornalismo? A experiência do jornalismo de defesa civil na América Latina. In anais do: Sociedade Brasileira de Pesquisa em Jornalismo, 2009a.

Advocacy Journalism in a Global Context. In: WAHL-JORGENSEN Karin; HANITZSCH, Thomas. The handbook of journalism studies. New York, Taylor and Francis: 2009b. p. 371-385

\section{Outros}

Acervo dos boletins "Prioridade Absoluta” produzidos entre 2000 e 2010. 
Original recebido em: 15/11/2011

Aceito para a publicação em: 20/05/2013

Elton Antunes possui graduação em Comunicação Social pela Universidade Federal de Minas Gerais (1988), mestrado em Sociologia pela Universidade Federal de Minas Gerais (1995) e doutorado em Comunicação e Cultura Contemporânea na UFBA (2007). Atualmente é professor da Universidade Federal de Minas Gerais e participa do Grupo de Pesquisa Imagem e Sociabilidade (Gris)

eantunes@ufmg.br / (31) 3409-6250

Carolina Silveira possui graduação em Comunicação Social pela Universidade Federal de Minas Gerais (2006), especialização em Elaboração, Gestão e Avaliação de Projetos Sociais (2007) pelo Departamento de Sociologia da Universidade Federal de Minas Gerais e mestrado em Comunicação e Sociabilidade Contemporânea, pelo Programa de Pós-graduação em Comunicação da Universidade Federal de Minas Gerais.

silveiracarolina@yahoo.com.br / (21) 6964-8788 